\title{
Clinical features of idiopathic megarectum and idiopathic megacolon
}

\author{
J M Gattuso, M A Kamm
}

\begin{abstract}
Background-Dilatation of the rectum and/or colon, in the absence of demonstrable organic disease, is an uncommon and poorly characterised condition.

Aims-To characterise the clinical and diagnostic features, and response to treatment, of patients with idiopathic megarectum (IMR) and idiopathic megacolon (IMC).

Methods-A retrospective review was undertaken of all patients operated on for these conditions over a 23 year period. In addition all patients treated over a three year period were prospectively studied by means of a questionnaire, contrast studies of the upper and lower intestine, spine $x$ rays to exclude spinal dysraphism, anorectal physiological studies, and assessment of clinical outcome. Patients with Hirschsprung's disease and other known
\end{abstract} causes of gut dilatation were excluded.

Results-(i) Retrospective study: Of 63 operated patients, 22 had IMR, 23 had IMR and IMC, and 18 had IMC only. Five patients with IMC had previous sigmoid volvulus, and three had associated nongastrointestinal congenital abnormalities. Faecal incontinence was always associated with rectal impaction and 14 patients $(82 \%)$ with IMR alone had had manual disimpaction. (ii) Prospective study: Twenty two patients had IMR, with a median rectal diameter of $10 \mathrm{~cm}$ (normal $<6.5 \mathrm{~cm}$ ). Six patients had IMC and one patient had IMR and IMC. Patients with IMR were significantly $(p=0.0007)$ younger than patients with IMC. All patients with IMR became symptomatic in childhood, compared with half the patients with IMC who developed symptoms as adults. Patients with IMR all presented with soiling and impaction, compared with patients with IMC whose symptoms were variable and included constipation or increased bowel frequency, pain, and variable need for laxatives. No upper gut dilatation was seen in either group of patients. Spinal dysraphism was seen in two of 18 patients with IMR and two of four with IMC, suggesting extrinsic denervation as a possible cause in a minority. Twelve of 22 patients with IMR had a maximum anal resting pressure below normal, indicating sphincter damage or inhibition. Both IMR and IMC patients had altered rectal sensitivity to distension, suggesting that despite lack of dilatation the rectum in IMC has altered viscoelasticity, tone, or sensory function. Fifteen of 22 patients with IMR were successfully managed with laxatives or enemas, but seven required surgery. Two of seven patients with IMC required surgery, including one for sigmoid volvulus. Conclusions-Patients with IMR differ clinically, diagnostically, and in their outcome from patients with IMC. These conditions demand specific investigation, and intensive treatment, to achieve optimum care.

(Gut 1997; 41: 93-99)

Keywords: idiopathic megarectum; idiopathic megacolon

Patients with intractable constipation can be divided into those who have a normal diameter gut and those who have gut dilatation. The latter include patients with Hirschsprung's disease, chronic idiopathic intestinal pseudoobstruction and idiopathic megacolon or megarectum. The last conditions of an idiopathically dilated colon and/or rectum appear to be clinically heterogenous, are very uncommon, and hence are often poorly managed.

This study aimed to characterise these conditions clinically. A large series of patients was defined precisely from the clinical, operative, and pathological aspects, by retrospectively studying all patients who underwent surgery at one hospital for these conditions over a 23 year period. To establish the clinical spectrum of all patients with this condition, including outcome, and to evaluate them consistently, we have also prospectively studied all patients with idiopathic megarectum or megacolon referred to the same hospital over a three year period.

\section{Methods}

In both the retrospective and prospective part of this study patients were divided into those with idiopathic megarectum (including a variable degree of sigmoid colon dilatation), total rectal and colonic dilatation, or megacolon with a normal size rectum. ${ }^{1}$

RETROSPECTIVE STUDY OF OPERATED PATIENTS The notes of patients classified as having idiopathic megarectum or megacolon who had surgery between 1968 and 1991 were reviewed. Patients were included only if the gut 
was dilated on preoperative contrast studies and at operation, and if other causes of gut dilatation such as Hirschsprung's disease had been excluded. The extent of gut dilatation was determined from written reports of preoperative contrast studies and intraoperative findings. Sixty three patients fulfilled these criteria.

Symptoms at presentation to our hospital, treatment before referral and at our hospital, and past medical, surgical, and family history were reviewed. The histology reports of biopsy and resection specimens were also reviewed.

PROSPECTIVE STUDY

All 29 patients with idiopathic megarectum or megacolon, attending St Mark's Hospital between 1992 and 1995, were prospectively investigated according to the protocol.

Hirschsprung's disease was excluded by the characteristic clinical features of soiling and faecal impaction down to the pelvic floor (both characteristic of idiopathic megarectum in contrast to Hirschsprung's disease), dilatation of the rectum down to the pelvic floor on contrast studies, and demonstration of the rectoanal inhibitory reflex. If the diagnosis remained uncertain full thickness rectal biopsy specimens were obtained to demonstrate the presence of intramural ganglia. The histology of the resection specimens of all patients who had surgery was also reviewed to ensure that Hirschsprung's disease or an intestinal neuropathy or myopathy had not been missed.

\section{Questionnaire}

A detailed questionnaire was completed, in the presence of a parent or carer where appropriate. This included information about the duration and severity of symptoms, other illnesses, family history, and treatment.

\section{Radiology}

All patients had lower gastrointestinal contrast studies performed, usually a water soluble contrast (Gastrografin) enema on unprepared bowel. A rectal diameter of greater than $6.5 \mathrm{~cm}$ in the lateral view, as measured on a line extending perpendicular to $S 2$, was regarded as abnormally enlarged. ${ }^{2}$

To exclude upper gut dilatation, and therefore chronic idiopathic intestinal pseudoobstruction, 21 patients also had an upper gastrointestinal barium study. Upper gut dilatation is uncommon without duodenal dilatation. As we wished to minimise the radiation exposure in these predominantly young patients, radiological investigation was limited to one radiograph, at 15 minutes after ingestion, as this was most likely to reveal any upper gut dilatation. In a further two patients a complete contrast study of the upper gut had been performed at the referring hospital.

Lumbar spine $x$ rays were performed in 23 patients to look for evidence of spinal dysraphism, to investigate the possibility of an abnormality of the extrinsic innervation to the hindgut as a cause of their condition.

\section{Anorectal physiological tests}

Anorectal physiological tests were performed in 29 patients. They were performed when the patient's bowel was as empty as possible, having been emptied either with enemas and laxatives or after manual disimpaction under general anaesthesia. If studies were performed after disimpaction they were undertaken a minimum of 10 days after the procedure, with the rectum having been kept empty by the use of laxatives or enemas. The normal range for these tests was derived from a prospective study of age and sex matched healthy volunteers, using identical techniques in our laboratory. ${ }^{3}$

A perineometer was used to measure the position of the perineum relative to the ischial tuberosities at rest and during straining and the degree of perineal descent calculated. ${ }^{4}$ Perianal light touch and pin prick (pain) sensation were tested. Anorectal manometry was performed with a closed water filled $3 \mathrm{~mm}$ microballoon and a station pull through technique. The following measurements were made: maximum resting anal pressure, functional anal canal length, and maximum voluntary contraction increment (mean of three measurements for each). Rectal sensation was assessed by inflating a rectal balloon with air at $60 \mathrm{ml}$ per minute to measure the threshold of sensation (first sensation), the volume at which the patient first had the urge to defaecate (urge volume), and the maximum tolerated volume. The mean of three such measurements was recorded. The presence or absence of the rectoanal inhibitory reflex ${ }^{56}$ was determined and the volume needed to elicit it recorded. The mucosal electrosensory threshold was assessed in the rectum $6 \mathrm{~cm}$ above the anal canal and in the centre of the anal canal with a bipolar ring electrode (Dantec, UK) mounted on a Foley urinary catheter. ${ }^{7} 8$ This electrode was connected to a constant current stimulator (Neuromatic 2000 MIC, Dantac, UK). Patients were asked to expel a simulated stool ( $50 \mathrm{ml}$ water filled balloon) while in the left lateral position. Any paradoxical contraction on defaecatory straining while attempting to expel a balloon filled with $50 \mathrm{ml}$ water ${ }^{9}{ }^{10}$ was recorded with either a concentric needle electrode sited within the external anal sphincter or with perianal self-adhesive surface electrodes. Right and left pudendal nerve latencies were measured with a St Mark's pudendal nerve stimulating electrode.

The rectoanal inhibitory reflex was further studied in nine patients using electrical stimulation applied to the rectal wall, ${ }^{11} 12$ to assess its possible value as an additional diagnostic test when the reflex cannot be induced with rectal distension. Nagasaki et al ${ }^{11}$ have shown in constipated children that electrical stimulation of the rectal mucosa can induce the rectoanal inhibitory reflex. This reflex is dependent on an intact intramural enteric innervation and independent of the extrinsic rectal innervation. ${ }^{1213}$ 
Clinical outcome

The response to laxatives and enemas, and the need for surgery, was recorded. The laxatives most commonly used in the management of these patients are osmotic laxatives, usually magnesium sulphate or lactulose, taken once or twice per day in a dose titrated to achieve regular daily bowel actions without excessively liquid stools and urgency. The use of these drugs is based on previous experience of trying different laxative regimes in these patients.

The need for surgery was based on the failure of medical therapy, either because of an unwillingness of the patients to continue taking laxatives or using enemas, or because of the failure of these substances to prevent recurrent faecal impaction. A further indication for surgery in patients with an idiopathic megacolon was the occurrence of volvulus.

\section{Results}

RETROSPECTIVE STUDY

Of the 63 patients studied 22 had idiopathic megarectum ( 7 female, median age 20 years, range 12-69), 23 had megarectum and megacolon ( 7 female, median age 27 years, range 12-69), and 18 had megacolon only (12 female, median age 40 years, range 22-66). Patients with idiopathic megacolon (and a normal diameter rectum) were significantly $(p=0.0009)$ older than patients with idiopathic megarectum. Five patients with a megacolon, of which three also had a megarectum, had had a previous sigmoid volvulus, and one further patient with idiopathic megacolon had had a volvulus of the splenic flexure.

Most patients presented with constipation, but documented bowel habit was very variable, from five times per day to only once every three months. The normal or greater than normal bowel frequency in some patients related to impaction with overflow, repeated attempts to defaecate, and a genuine high frequency in a small proportion.

Faecal incontinence was always associated with rectal faecal impaction and occurred in 17 patients $(77 \%)$ with isolated megarectum and 13 patients $(57 \%)$ with megarectum and megacolon. Most patients $(n=14,82 \%)$ with idiopathic megarectum alone, and approximately half $(n=6,46 \%)$ of those with associated proximal colonic dilatation, had undergone manual disimpaction under general anaesthesia.

Abdominal distension was more common than abdominal pain, occurring in $60 \%$ and

TABLE 1 Age at onset of symptoms and age at surgery in patients having surgery over a 23 year period (1968-91) for idiopathic megarectum and/or megacolon

\begin{tabular}{|c|c|c|c|c|c|c|}
\hline \multirow[b]{2}{*}{ Age (y) } & \multicolumn{2}{|c|}{$\begin{array}{l}\text { Idiopathic } \\
\text { megarectum }(n=22)\end{array}$} & \multicolumn{2}{|c|}{$\begin{array}{l}\text { Idiopathic megarectum } \\
\text { and megacolon }(n=23)\end{array}$} & \multicolumn{2}{|c|}{$\begin{array}{l}\text { Idiopathic } \\
\text { megacolon }(n=18)\end{array}$} \\
\hline & $\begin{array}{l}\text { Age at } \\
\text { onset }\end{array}$ & $\begin{array}{l}\text { Age at } \\
\text { operation }\end{array}$ & $\begin{array}{l}\text { Age at } \\
\text { onset }\end{array}$ & $\begin{array}{l}\text { Age at } \\
\text { operation }\end{array}$ & $\begin{array}{l}\text { Age at } \\
\text { onset }\end{array}$ & $\begin{array}{l}\text { Age at } \\
\text { operation }\end{array}$ \\
\hline $\begin{array}{l}<5 \\
5-10 \\
11-20 \\
>20\end{array}$ & $\begin{array}{c}11(50 \%) \\
7(32 \%) \\
1(5 \%) \\
2(2 \%)\end{array}$ & $\begin{array}{l}0 \\
0 \\
13(59 \%) \\
9(41 \%)\end{array}$ & $\begin{array}{l}4(17 \%) \\
8(35 \%) \\
5(22 \%) \\
6(26 \%)\end{array}$ & $\begin{array}{l}0 \\
0 \\
9(39 \%) \\
14(61 \%)\end{array}$ & $\begin{array}{l}0 \\
7(39 \%) \\
4(22 \%) \\
7(39 \%)\end{array}$ & $\begin{array}{l}0 \\
0 \\
0 \\
18(100 \%)\end{array}$ \\
\hline
\end{tabular}

$40 \%$ of patients respectively, and occurred in all three patient groups. No patient experienced vomiting. Table 1 shows the age at onset of symptoms and the age at operation in the three patient groups. Ninety per cent of patients with idiopathic megarectum were dependent on laxatives, almost all starting in childhood. In contrast $55 \%$ of patients with idiopathic megarectum and megacolon and $72 \%$ of patients with megacolon alone used laxatives, often intermittently.

No formal intelligence or psychological testing had been undertaken in these patients. However four patients with idiopathic megarectum and two with megarectum and megacolon were noted to have marked mental retardation. The majority of patients appeared to be within the normal intelligence range. Seven patients, all with a megarectum, with or without megacolon, had documented depression, often associated with schooling difficulties. No such history was noted in the patients with idiopathic megacolon only.

Most patients had no significant family history. In four patients there was a family history of constipation, no episodes of which required hospital admission. One patient with idiopathic megarectum and megacolon had a brother with Hirschsprung's disease. Isolated congenital abnormalities were present in three patients with idiopathic megarectum: one had congenital heart disease, one agenesis of one ear, and one agenesis of one iris.

A rectoanal inhibitory reflex was elicited in nine of $18(50 \%)$ patients with idiopathic megarectum, in 12 of $16(75 \%)$ patients with idiopathic megarectum and megacolon, and in nine of $10(90 \%)$ patients with idiopathic megacolon. In all 63 patients histology of preoperative full thickness rectal biopsy and resection specimens showed idiopathic megabowel and did not show any features of Hirschsprung's disease or of intestinal myopathy or neuropathy.

\section{PROSPECTIVE STUDY}

Twenty two patients (seven women) had idiopathic megarectum, with a dilated rectum of median diameter $10 \mathrm{~cm}$ (range 7-15 cm), no distal narrow segment, and variable dilatation of the sigmoid colon. Six patients (three women) had idiopathic megacolon, with a dilated sigmoid and proximal colon but a normal diameter rectum, and one patient had total colonic and rectal dilatation (rectum 9.5 $\mathrm{cm}$ diameter).

\section{Questionnaire}

Patients with idiopathic megarectum presented to our hospital at a median age of 19 years (range 13-36). Of these patients, 12 became symptomatic in infancy, nine at age 5-10 years and one at age 18 years. The six patients with idiopathic megacolon were significantly $(p=0.0007$ ) older (median 42 years, range 37-59) than the patients with megarectum. Three patients with megacolon had constipation requiring laxatives in childhood; the 
TABLE 2 Symptoms in patients prospectively studied with idiopathic megarectum or idiopathic megacolon

\begin{tabular}{|c|c|c|}
\hline & $\begin{array}{l}\text { Idiopathic } \\
\text { megarectum } \\
(n=22)\end{array}$ & $\begin{array}{l}\text { Idiopathic } \\
\text { megacolon } \\
(n=6)\end{array}$ \\
\hline Faecal incontinence & 22 & 0 \\
\hline Faecal impaction & 22 & 0 \\
\hline $\begin{array}{l}\text { Previous manual disimpaction } \\
\text { under general anaesthesia }\end{array}$ & 19 & 0 \\
\hline Abdominal pain & 19 & 6 \\
\hline Abdominal distension & 17 & 5 \\
\hline Nausea or vomiting & 4 & 1 \\
\hline Sense of incomplete evacuation & $16(\text { of } 18)^{\star}$ & 3 \\
\hline Digital extraction of faeces & $1(\mathrm{f})$ & $1(\mathrm{f})$ \\
\hline Nocturia & 3 & \\
\hline
\end{tabular}

*Only 18 patients able to understand the question fully; f, female.

other three had had no bowel related symptoms until adulthood. Table 2 summarises the presenting symptoms. Faecal incontinence, that is passive soiling, associated with rectal faecal impaction, occurred in all patients with idiopathic megarectum. Eight of these patients denied faecal incontinence on direct questioning, despite it being obvious on clinical examination.

In patients with idiopathic megarectum abdominal pain and distension was associated with faecal impaction and relieved by bowel evacuation. Bowel evacuation also relieved abdominal pain and distension in three of the patients with idiopathic megacolon, but in two patients there were no obvious initiating or relieving factors for their pain. A variety of laxatives, including suppositories and enemas, had been tried by all the patients with idiopathic megarectum. Symptoms in patients with idiopathic megacolon were more variable, including constipation, increased bowel frequency, abdominal pain, and bloating; a constant need for laxatives was not seen in these patients.

Three patients with idiopathic megarectum experienced nocturia, although it occurred infrequently in one patient. No patient had urinary incontinence or a history of urinary tract infections.

No formal IQ tests or psychological profiles were performed. However, five patients with idiopathic megarectum were mentally retarded, and one had severe autism. Another patient had a history of manic depression controlled by lithium.

The only significant medical or surgical history in any of the patients was manual disimpaction under general anaesthesia in patients with idiopathic megarectum. No patient had a history of physical or sexual abuse, a history of precipitating event such as anal fissure, or a relevant family history. Thyroid function tests and calcium levels were normal in all patients.

\section{Radiology}

Seventeen of the 22 patients with idiopathic megarectum, five of the six patients with idiopathic megacolon, and the one patient with combined megacolon and megarectum had upper gastrointestinal contrast studies. No duodenal dilatation was seen in any patient.

Twenty three patients had lumbar spine $x$ rays. Of these, two of 18 with idiopathic megarectum, and two of four with idiopathic megacolon, had spina bifida occulta. The patient with colonic and rectal dilatation had normal spine radiographs.

\section{Anorectal physiological testing}

There was no abnormal perineal descent in any of the patients studied. The results of anorectal physiological testing are shown in table 3 . The maximum resting anal pressure was lower than normal in 12 patients with idiopathic megarectum. The voluntary contraction increment was normal in all except three patients with idiopathic megarectum. Two had a low or absent voluntary contraction increment, but normal cough increment, suggesting an intact external anal sphincter but lack of voluntary effort.

Perianal sensation was normal in all patients. Rectal sensation to electrical stimulation, a useful marker of possible neurological abnormality, ${ }^{8}$ was elevated in most of the patients with idiopathic megarectum, five having no rectal sensation at maximal stimulation and only six being within the normal range. Rectal electrosensation was within normal limits in patients with idiopathic megacolon. Rectal sensitivity to balloon distension was diminished both in patients with idiopathic megarectum and idiopathic megacolon.

In the two patients with a megarectum and occult spina bifida the rectal sensory threshold was well above the normal range (43 and 99 $\mathrm{mA}$ ). In the two patients with a megacolon and occult spina bifida the rectal sensory threshold to electrical stimulation was normal.

TABLE 3 Anorectal physiological testing in 22 patients with idiopathic megarectum and six patients with idiopathic megacolon studied prospectively

\begin{tabular}{lccr}
\hline & $\begin{array}{l}\text { Idiopathic } \\
\text { megarecturm }\end{array}$ & \multicolumn{1}{l}{$\begin{array}{l}\text { Idiopathic } \\
\text { megacolon }\end{array}$} & Controls \\
\hline Maximum resting anal pressure $\left(\mathrm{cm} \mathrm{H}_{2} \mathrm{O}\right)$ & $56(20-110)$ & $100(36-136)$ & $97(74-132)$ \\
Voluntary contraction increment $(\mathrm{cm} \mathrm{H} \mathrm{O})$ & $91(0-160)$ & $102(41-200)$ & $119(56-189)$ \\
Anal canal length $(\mathrm{cm})$ & $3 \cdot 6(2 \cdot 5-5)$ & $3 \cdot 8(3 \cdot 5-4 \cdot 5)$ & $4(3 \cdot 4-4 \cdot 6)$ \\
First sensation $(\mathrm{ml})$ & $215^{\star}(20-680)$ & $103(50-180)$ & $46(29-72)$ \\
Urge volume (ml) & $244^{\star \star}(90-633)$ & $239(143-433)$ & $92(70-125)$ \\
Maximum tolerated (ml) & $518^{\star \star \star}(150-950)$ & $411(250-683)$ & $188(145-234)$ \\
Anal sensation (mAmp) & $7(3-11)$ & $6(3-8)$ & $5(3-8)$ \\
Rectal sensation (mAmp) & $39^{\star \star \star \star}(17-78)$ & $28(20-35)$ & $24(15-35)$ \\
\hline
\end{tabular}

Control values from the normal range prospectively determined in age and sex matched healthy volunteers in our laboratory. ${ }^{3}$ Data were normally distributed and results are given as mean with range in parentheses.

$\star$ One patient had no sensation on inflation with $>1000 \mathrm{ml} ; \star \star$ four patients had no urge sensation; $\star \star \star$ four patients had no sensation of discomfort with $>1000 \mathrm{ml} ; \star \star \star \star$ five patients had no sensation at maximal stimulation (99.9 mAmp). 
The rectoanal inhibitory reflex was elicited by balloon distension in 14 of $22(64 \%)$ patients with idiopathic megarectum and in five of the six patients with idiopathic megacolon.

Only one patient with idiopathic megarectum was able to expel the simulated stool, but four of the six patients with idiopathic megacolon were able to do so. Paradoxical contraction of the external anal sphincter on attempted rectal evacuation was seen in half of the patients with idiopathic megarectum but in only one of those with idiopathic megacolon. Pudendal nerve latencies were normal in all patients.

The rectoanal inhibitory reflex could be elicited in four of seven patients with idiopathic megarectum using a rectal inflation volume of $50 \mathrm{ml}$ air. In the other three it could not be elicited using volumes up to the maximum tolerated volume. It was only possible to elicit the reflex using electrical stimulation in one of these seven patients; in four of these patients the stimulus caused pain without reaching the level required to induce sphincter relaxation. Of two patients with idiopathic megacolon, both with normal rectoanal inhibitory reflexes on balloon insufflation and a normal rectal electrosensory threshold, a reflex was induced by electrical stimulation in only one.

\section{Clinical outcome}

Of the 22 patients with idiopathic megarectum 15 were successfully established and maintained on maintenance laxatives, and/or enemas. Seven patients ( 3 female) required surgery (colectomy and ileorectal anastomosis $(n=2)$, Duhamel procedure $(n=2)$, or ileostomy formation $(n=1)$; two patients were booked for surgery elsewhere). The type of surgery was determined by the rectal diameter, with colectomy and ileorectal anastomosis being the preferred procedure but only being possible if the rectal diameter was small enough. ${ }^{14-17}$

One patient with idiopathic megacolon, which was associated with radiologically documented recurrent sigmoid volvulus, had a left hemicolectomy. The other patients with idiopathic megacolon were successfully managed with intermittent laxative use. The patient with idiopathic megarectum and megacolon had a colectomy with ileorectal anastomosis, which successfully relieved intractable abdominal pain and bloating.

\section{Discussion}

To our knowledge this is the first prospective unselected series of patients studied, the literature consisting mainly of retrospective surgical series. Although this study comprised patients referred to a tertiary centre, we believe that patients with these conditions are likely to find their way to such centres because of their rarity and the difficulty they pose with management. They are therefore likely to be representative of patients with these disorders, although it is possible that patients with milder forms of these conditions remain unrecognised and untreated in the community. The true prevalence of these disorders is unknown.

\section{Idiopathic megarectum}

We have shown that patients with idiopathic megarectum, with or without more proximal colonic dilatation, form a clinically distinct group. We have used radiological criteria to separate the patient groups in this study, although these appeared to correlate well with the clinical presentation. In contrast Verduron et $a l^{18}$ used rectal volume-pressure testing to classify a group of patients they studied. Barnes et $a l^{19}$ divided their patients with an idiopathically dilated bowel into those with the onset of symptoms before or after the age of 10 . Those whose condition started at the younger age were more likely to have a megarectum, in keeping with our findings. However, there was overlap with rectal or colonic dilatation occurring in both age groups. This distinction based on age is therefore not absolutely reliable.

These patients with idiopathic megarectum are clinically different from patients who have a dilated large bowel with a normal diameter rectum, the latter being more appropriately labelled as having idiopathic megacolon. Two thirds of patients presenting to our hospital were able to be restored to good health with drug therapy, but a third required surgery.

Almost all patients with idiopathic megarectum developed symptoms in childhood or adolescence, and it occurred more commonly in males. Only a minority of our patients appeared to have a marked intellectual deficit, although others have recognised the association of a dilated bowel with intellectual impairment or psychiatric disease. ${ }^{20}$ Whether these associations are due to a shared abnormality of brain and gut neurological development, to long term use of psychotropic drugs, or to the effects of suppressed defaecation, remain unknown. In patients with idiopathic megarectum the symptoms started in childhood or adolescence, and were due to rectal faecal impaction. In most patients this was associated with marked faecal incontinence, a symptom which at this age can have profound psychological and social consequences.

It is likely that patients with idiopathic megarectum have a number of differing underlying aetiologies, including behavioural and neurophysiological. In contrast to patients with chronic idiopathic intestinal pseudoobstruction $^{21}$ and slow transit idiopathic constipation, ${ }^{22-25}$ this condition appears to be an isolated abnormality, with no upper gastrointestinal or urinary abnormalities. Upper gut radiological studies were normal and patients responded clinically to keeping the rectum empty. Further evidence comes from radioisotope transit studies from the stomach and small bowel in these patients, which have not revealed major disturbances of function. ${ }^{26}$

Rectal sensation to distension was impaired in these patients, but this is to be expected 
when the rectum is dilated. However, the rectal sensory threshold to electrical stimulation was also elevated, raising the possibility of an underlying neurological disorder. This test, which probably conveys sensation via unmyelinated type $C$ afferent fibres and extrinsic pelvic afferent nerves, is a useful marker of extrinsic denervation. ${ }^{8}$ We cannot exclude however that this raised threshold was not related to retained stool in the rectum, although the presence of stool usually blocks conduction completely, preventing any measurement from being obtained. Although an abnormality of extrinsic innervation may be aetiologically important in some patients, only two of our patients with idiopathic megarectum had spinal dysraphism, suggesting that this condition is not simply related to occult spina bifida.

The presence of a rectoanal inhibitory reflex in most of these patients indicates an intact intramural enteric innervation. We could not elicit the reflex by electrostimulation despite patients feeling the stimulus, ensuring the electrodes' mucosal contact, and the known intact architecture of the intrinsic enteric innervation in this condition. ${ }^{27}$ This may reflect altered responsiveness of the intrinsic nerves, as is seen in idiopathic constipation. ${ }^{8} 12$ We could not confirm the value of electrical stimulation as a diagnostic test in patients with a dilated rectum.

The low resting anal canal pressure in these patients is an indicator predominantly of impaired internal anal sphincter function. ${ }^{28} 29$ This may relate to damage caused by manual disimpaction under general anaesthesia, ${ }^{30}$ an inhibitory effect of large volume of rectal stool (although these patients were studied with as empty a rectum as possible), or an intrinsic abnormality of the sphincter itself (possibly shared with a smooth muscle abnormality of the rectum). The role, if any, of prolonged rectal distension in lowering anal tone is unknown, although Read and Abouzekry ${ }^{31}$ showed that in elderly patients rectal faecal impaction was not associated with any lowering of the anal pressures. In all patients, the external anal sphincter was functionally intact, as reflected in the normal voluntary contraction. ${ }^{29}$

Of those patients managed medically, anorectal physiological assessment did not distinguish between those patients who would successfully use oral laxatives and establish a "normal" defaecatory pattern, without undue faecal urgency and full continence, and those who would be dependent on regular phosphate enemas to empty the rectum of formed stool. Paradoxical contraction on defaecatory straining and inability to expel a simulated stool has previously been reported in these patients ${ }^{32}{ }^{33}$; its presence did not predict the outcome of medical management. Unlike patients with functional bowel disorders and a non-dilated gut, ${ }^{34}{ }^{35}$ we found no history of sexual or physical abuse.

These young patients of both sexes are difficult to manage. Our patients required continuous use of oral laxatives or enemas to prevent reimpaction. Faecal incontinence was mainly associated with rectal impaction, and not a refractory "psychological" problem. Maintenance treatment for these patients is lifelong, ${ }^{19}$ and this needs to be impressed on the patients and their carers.

\section{Idiopathic megacolon}

In contrast to patients with idiopathic megarectum, patients with idiopathic megacolon had the onset of symptoms either in childhood or adulthood. There may be a difference in aetiology between those who develop symptoms at these two different times in life.

Megacolon remains relatively poorly defined from the morphological point of view. Normal values for proximal and sigmoid colon diameters on single contrast enemas ${ }^{36}$ and double contrast enemas ${ }^{2}$ have been reported. However, there is a wide normal range and the diagnosis of megacolon remains subjective. During the prospective study we saw very few of these patients, whose condition appears to be rarer than idiopathic megarectum.

Rectal sensation to distension was impaired in the patients with a megacolon despite a lack of radiological rectal enlargement, suggesting increased rectal wall compliance, as part of an abnormal propensity to dilatation throughout the large bowel.

Two of the patients with a megacolon had spinal dysraphism. This suggests that abnormal extrinsic innervation may be aetiologically important in this condition, although the numbers were too small to be statistically certain of the importance of this finding. The normal rectal electrosensory threshold in these two patients suggests that if extrinsic denervation is aetiologically important, the colon, and not the rectum, is affected.

Drug treatment was sometimes successful, and sometimes was only needed intermittently. Surgery is clearly indicated if there is evidence of volvulus, and colectomy with ileorectal anastomosis should be considered in those with disabling symptoms. Volvulus may not be an uncommon complication of this condition. Conversely it is our feeling that most patients with sigmoid volvulus have an underlying megacolon, although prospective studies are required to establish this conclusively.

1 Lane RHS, Todd IP. Idiopathic megacolon: a review of 42 cases. Br f Surg 1977; 64: 305-10.

2 Preston DM, Lennard-Jones JE, Thomas BM. Towards a radiologic definition of idiopathic megacolon. Gastrointest Radiol 1985; 10: 167-9.

3 Jameson JS, Chia YW, Kamm MA, Speakman CTM, Chye YH, Henry MM. Effect of age, sex and parity on anorectal function. $B r \mathcal{F}$ Surg 1994; 81: 1689-92.

4 Henry MM, Parks AG, Swash M. The pelvic floor musculature in the descending perineum syndrome. $\mathrm{Br} \mathcal{J}$ Surg 1982; 69: 470-2.

5 Denny-Brown D, Robertson EG. An investigation of the nervous control of defaecation. Brain 1935; 58: 256-310.

6 Schuster MM. The riddle of the sphincters. Gastroenterolog 1975; 69: 249-62.

7 Roe AM, Bartolo DCC, Mortensen NJMcC. New method for assessment of anal sensation in various anorectal disorders. Brf Surg 1986; 73: 310-2.

$8 \mathrm{Kamm} \mathrm{MA,} \mathrm{Lennard-Jones} \mathrm{JE.} \mathrm{Rectal} \mathrm{mucosal} \mathrm{electro-}$ sensory testing - evidence for a rectal sensory neuropathy in idiopathic constipation. Dis Colon Rectum 1990; 33:
in in idiopath.

9 Kuijpers HC, Bleijenberg G. The spastic pelvic floor syndrome. Dis Colon Rectum 1985; 28: 669-72. 
10 Preston DM, Lennard-Jones JE. Anismus in chronic constipation. Dig Dis Sci 1985; 30: 413-8.

11 Nagasaki A, Ikeda K, Suita S, Sumitomo K. Induction of the rectoanal reflex by electric stimulation. A diagnostic aid for Hirschsprung's disease. Dis Colon Rectum 1984; 27: 598-601.

12 Kamm MA, Lennard-Jones JE, Nicholls RJ. Evaluation of the intrinsic innervation of the internal anal sphincter using electrical stimulation. Gut 1989; 30: 935-8.

13 Lubowski DZ, Nicholls RJ, Swash M, Jordan MJ. Neural control of internal anal sphincter function. $B r f$ Surg 1987; 74: 668-70.

14 Duhamel B. Retrorectal and transanal pull-through procedure for the treatment of Hirschsprung's disease. Dis Colon Rectum 1964; 7: 455-8

15 Stabile G, Kamm MA, Hawley PR, Lennard-Jones JE. Results of Duhamel operation in the treatment of idiopathic megarectum and megacolon. Br f Surg 1991; idiopathic

16 Stabile G, Kamm MA, Hawley PR, Lennard-Jones JE. Colectomy for idiopathic megarectum and megacolon. Gut 1991; 32: 1538-40.

17 Kamm MA, Stabile G. Management of idiopathic megarectum and megacolon. Br f Surg 1991; 78: 899-900.

18 Verduron A, Devroede G, Bouchoucha $M$, Arhan $P$ Schang J-C, Poisson J, et al. Megarectum. Dig Dis Sci 1988; 33: 11 164-74.

19 Barnes PRH, Lennard-Jones JE, Hawley PR, Todd IP Hirschsprung's disease and idiopathic megacolon in adults and adolescents. Gut 1986; 27: 534-41.

20 Ehrentheil OF. Megacolon in psychotic patients. Gastroenterology $1955 ; 29 \cdot 285-94$

21 Christensen J, Dent J, Malagelada JR, Wingate DL. Pseudoobstruction. Gastroenterol Int 1990; 3: 107-19.

22 Bannister JJ, Lawrence WT, Smith A, Thoma DG Read NW. Urological abnormalities in young women with Read NW. Urological abnormalities in youn

23 MacDonald A, Shearer M, Paterson PJ, Finlay IG. Relationship between outlet obstruction constipation and obstructed urinary flow. Br F Surg 1991; 78: 693-5.

24 Van der Sijp JRM, Kamm MA, Nightingale JMD,
Disturbed gastric and small bowel transit in severe idiopathic constipation. Dig Dis Sci 1993; 38: 837-44.

25 Lemieux M-C, Kamm MA, Fowler CJ. Bowel dysfunction in young women with urinary retention. Gut 1993; 34: 1397-9.

26 Gattuso JM, Kamm MA, Morris G, Britton KE. Gastrointestinal transit in patients with idiopathic megarectum. Dis Colon Rectum 1996; 39: 1044-50.

27 Gattuso JM, Kamm MA, Talbot ICT. Pathology of idiopathic megarectum and megacolon. In: Kamm MA, Lennard-Jones JE, eds. Constipation. Petersfield: Wrightson Biomedical Publishing.

28 Frenckner B, Euler CV. Influence of pudendal block on the function of the anal sphincters. Gut 1975; 16: 482-9.

29 Read NW, Sun WM. Anorectal manometry. In: Henry MM, Swash M, eds. The pelvic floor. 2nd edn. 1992: MM, S.

30 Gattuso JM, Kamm MA, Halligan SM, Bartram CI. The anal sphincter in idiopathic megarectum: the effects of manual disimpaction under general anaesthetic. Dis Colon Rectum 1996; 39: 435-9.

31 Read NW, Abouzekry L. Why do patients with faecal impaction have faecal incontinence. Gut 1986; 27: 283-7.

32 Barnes PRH, Lennard-Jones JE. Balloon expulsion from the rectum in constipation of different types. Gut 1985; 26: 1049-52.

33 Barnes PRH, Lennard-Jones JE. Function of the striated anal sphincter during straining in control subjects and constipated patients with a radiologically normal rectum or idiopathic megacolon. Int 7 Colorectal Dis 1988; 3: $207-9$.

34 Drossman DA, Leserman J, Nachman G, Li Z, Gluck H, Toomey TC, et al. Sexual and physical abuse in women with functional or organic gastrointestinal disorders. Ann with functional or organic gastroir

35 Talley NJ, Helgeson S, Zinsmeister AR. Are sexual and physical abuse linked to functional gastrointestinal disorders. Gastroenterology 1992; 102 (suppl): A523.

36 Patriquin H, Martelli H, Devroede G. Barium enema in chronic constipation: is it meaningful? Gastroenterology 1978; 75: 619-22. 